\title{
NATURAL LANGUAGE PROCESSING AND BIM IN AECO SECTOR: A STATE OF THE ART
}

\author{
GIUSEPPE MARTINO DI GIUDA, MIRKO LOCATELLI, and ELENA SEGHEZZI \\ ABC Department, Politecnico di Milano, Milano, Italy
}

\begin{abstract}
The research provides state-of-the-art theories, methods, and applications of Natural Language Processing in a BIM approach to define advantages, weaknesses, and potential developments. Traditionally, the design and construction process requirements are expressed through verbal qualitative evaluations instead of using numerical and structured data. Information modeling and management methods can hardly manage requirements expressed by means of qualitative and unstructured expressions. This paper aims to define the state of the art on Natural Language Processing applications for the numerical translation of basic design requirements in the AECO sector. The major advantages of this research would be the optimization and automation of numerical definition and validation of requirements in a structured data form. Structured data can, in fact, be easily managed in a BIM approach. NLP supporting information modeling methods allows the application of requirements engineering and management techniques to handle construction processes from a datadriven perspective. An investigation of the setting of a decision support system, based on NLP, for the definition and validation of requirements in the early stages of the construction process, is also provided as a potential further development.
\end{abstract}

Keywords: NLP, Computational linguistic, Requirements engineering, Requirements management, Building information modeling, Information management, Data driven process.

\section{INTRODUCTION}

\subsection{Lack of Requirements Definition and Management in AECO Industry}

AECO sector (Architecture, Engineering, Construction, and Property) is affected by poor requirement management, identification, and traceability that affects the entire construction process (Yu et al. 2005, Arayici and Ahmed 2006). Requirements are the basis of each project, as they define what stakeholders and users need and what the final product should satisfy.

Requirements are essential for planning, proper risk management, information exchange, and design modification control (Hull et al. 2005); they are fundamental for the preliminary-design phase and the design and construction process (Yu et al. 2010). Requirements that are wellexpressed must be unambiguous, consistent, complete, feasible, neutral to design solutions, traceable, indispensable, synthetic, and verifiable (Young 2004).

\subsection{AECO Document-based Information Flow}

In recent years, the AECO industry is experiencing a radical change due to the increasingly pervasive application of information modeling. However, information exchange is based on documents, especially during the preliminary phase, and AECO information flow can still be 
considered document-based and not data model-based. Semi-structured and unstructured documents are an essential part of the overall project information resources (Opitz et al. 2014). In the AECO industry, requirements are defined and exchanged in natural language through text documents; natural language is pervasive. It is probably the best and richest form of knowledge representation and, therefore, cannot be replaced as the method of requirement definition during the briefing phase. However, this richness makes it difficult to automatically manage the knowledge in narrative documents (Mich and Garigliano 2014). Engineers and architects need semi-formal and formal models to work with; on the contrary, projects start with the definition of textual requirements in natural language, which may be inadequate because they are incomplete or ambiguous. The operation of identifying and translating textual requirements into semi-formal or formal requirements is usually manual, therefore error-prone (Arellano et al. 2015).

In requirement definition and management, some research has applied Natural Language Processing methods to overcome these problems (Ryan 1993, Ambriola and Gervasi 1997, Arellano et al. 2015). The complete definition of the initial requirements is fundamental for creating information models and information management processes; NLP can be performed to translate natural human language into structured digital entities. Aiming to better explain current and future implementations of NLP for information modeling in the AECO field, an overview of NLP's basic theories and latest developments is provided.

\subsection{Brief History and Development of NLP}

NLP is an artificial intelligence (AI) subfield that aims at making computers able to process natural human language (Cherpas 1992, Zhang and El-Gohary 2015).

Summarizing, NLP is a multidisciplinary field that involves humanistic knowledge, mathematical-statistical, and computer science competencies, aiming to process natural human languages using computers (Lenci et al. 2005). By definition, natural human language is considered ambiguous and mutable. On the other hand, machine language is structured, formal, univocal, and based on the bit (I/0), so that computers represent linguistic objects in nonlinguistic ways (Espunya i Prat 1994).

The history of computational linguistics has seen the succession of two main approaches: Rule-based approach and Corpora/Statistical-based approach. The main innovations and changes in the NLP field until the late 90s are shown in the timeline in Figure 1.

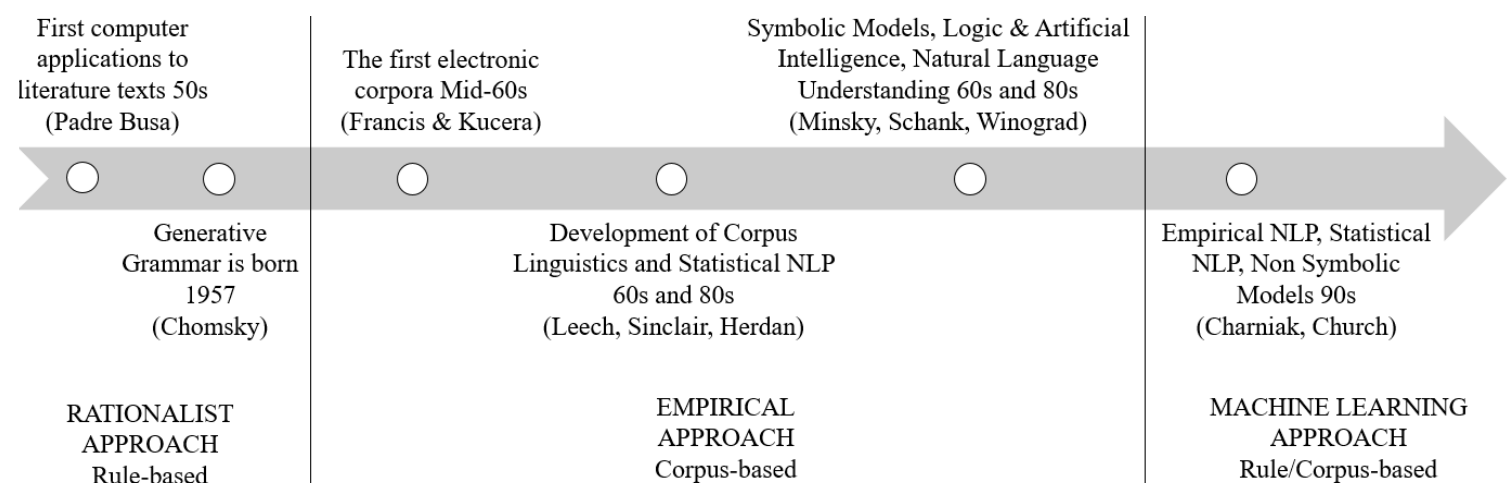

Figure 1. Computational linguistic timeline, from $50 \mathrm{~s}$ to $90 \mathrm{~s}$. 


\subsection{Recent Approach to NLP Based on Deep Learning}

NLP must deal with the ambiguous and inconsistent nature of human language. The latest NLP techniques privilege the use of machine learning algorithms based on Artificial Neural Network (ANNs). To manage the ambiguity of natural language, modern NLP relies on mixed methods that involve Rule-based, Corpora-based and Machine Learning (ML) approaches based on ANNs, that allow automatic modeling through learning processes (Callison-Burch and Osborne 2004). NLP techniques based on ANNs seem to have more chance of success due to various reasons. ANNs' characteristics are reported in Table 1.

Table 1. ANNs' potential characteristic and applications within the NLP field.

\begin{tabular}{l}
\hline ANNs' characteristic \\
\hline ANNs can manage noisy and ambiguous data from the human natural language and they are very similar to the \\
human method of learning (Rumelhart et al. 1987). \\
ANNs can overcome lack of data, which can be summarized in the phrase "Fill in the blank". \\
ANNs are very powerful pattern recognizers and classifiers (Jain and Pathak 2014).
\end{tabular}

NLP based on ANNs can translate natural language documents into formal entities and resources (Callison-Burch and Osborne 2004). However, ANNs do not explain their structure or the connections between the neurons that are created during the training phase: this phenomenon is called the black-box effect (Waziri et al. 2017).

\section{NLP AND BIM}

\subsection{AECO Application Fields}

Table 2 shows the main studies classified by field of application and sorted chronologically. The thematic and chronological subdivision allows to investigate the presence or absence of application cases and the evolution of the research in various phases of the construction process.

\subsection{NLP and BIM for Requirements Engineering and Management in AECO industry}

Research and applications on Requirements Engineering (RsE) in Systems Engineering (SE) are limited and not detailed in the AECO sector; there is also a lack of researches and application cases on Requirements Management (RsM) field (Yu and Chan 2009). Different applications of Natural Language Processing to the Requirements Engineering sector have been tested (Ambriola and Gervasi 1997, Ryan 1993). Applications include the use of NLP to extract ontologies from requirements in a specific knowledge domain and the use of NLP to verify consistency and/or completion of requirements (Arellano et al. 2015).

In the AECO sector, NLP can support the client to express and define his own requirements through formal entities. The modeling process of the client's requirements could increase the capacity of managing the construction process. The application of NLP during the definition, verification, and validation of project requirements can mitigate the risk of overcoming costs, time and budget, and support quality monitoring. An automated or semi-automated translation of narrative information into formal entities is a mandatory step for the application of Building Information Modeling approaches, which can be extended to an Information and Knowledge modeling and management by the semantic modeling of the requirements through NLP.

In a truly digitalized AECO industry, semantic information must be digitized and codified to make it unequivocally machine-readable; from this point of view, current BIM methodology shows limits and issues during the preliminary phase (Simeone and Cursi 2016). Requirements 
identified and defined in the briefing phase can be modeled and shared through semantic modeling methods in order to achieve a fully data-driven construction process (Beetz et al. 2005). The semantic enrichment of the information modeling process passes through applications derived from the semantic web. AECO sector sees an amount of experimental applications of semantic modeling of the knowledge domain based on ontologies (Beetz et al. 2005, Pauwels et al. 2019). The definition of ontologies describes them as formal and explicit specifications of shared conceptualizations (Gruber 1995). A requirement specification has no difference to an ontology, namely an explicit and shared conceptualization of a need and as such modeled.

Table 2. Applications of NLP in AECO sector.

\begin{tabular}{|c|c|c|}
\hline AECO field & NLP application & Main goal \\
\hline $\begin{array}{l}\text { Information } \\
\text { management }\end{array}$ & $\begin{array}{l}\text { Automated hierarchical document classification } \\
\text { system (Caldas and Soibelman 2003). } \\
\text { Explicit semantic analysis for product model } \\
\text { retrieval in construction industry (Liu et al. } \\
\text { 2017). } \\
\text { Construction Project Key-Phrase Network } \\
\text { system for the representation of unstructured } \\
\text { documents (Nedeljkovic and Kovašević 2017). } \\
\text { Natural-language-based intelligent retrieval } \\
\text { engine for BIM object databases (Wu et al. } \\
\text { 2019). }\end{array}$ & $\begin{array}{l}\text { Improve information organization and access in } \\
\text { construction management information databases. } \\
\text { Build up a retrieval system for BIM product models, } \\
\text { improving information extraction. } \\
\text { Improve acquisition, analysis, and reuse of relevant } \\
\text { information in an integral form visualizing valuable } \\
\text { project facts. } \\
\text { Improve BIM object query using semantic } \\
\text { information. }\end{array}$ \\
\hline $\begin{array}{l}\text { Procurement } \\
\text { management }\end{array}$ & $\begin{array}{l}\text { Automatic model of contract risk evaluation in } \\
\text { international construction projects using rule- } \\
\text { based NLP (Lee et al. 2019). } \\
\text { NLP to analyze construction project contracts } \\
\text { and correspondence (Marzouk and Enaba } \\
\text { 2019). }\end{array}$ & $\begin{array}{l}\text { Support contract management for construction } \\
\text { companies automatically detecting risky clauses in } \\
\text { contract documents. } \\
\text { Help project parties to figure out obligations and } \\
\text { reduce time and effort for contract analysis. }\end{array}$ \\
\hline $\begin{array}{l}\text { Risk } \\
\text { management } \\
\text { Requirement } \\
\text { management }\end{array}$ & $\begin{array}{l}\text { Analysis of bidding documents based on NLP } \\
\text { systems (Lee and Yi 2017). } \\
\text { NLP to detect defects in the requirement } \\
\text { documents (Ferrari } \text { et al. 2018). } \\
\text { Automated requirements identification from } \\
\text { contracts through a classification model based } \\
\text { on Naïve Bayes (Le et al. 2019). }\end{array}$ & $\begin{array}{l}\text { Construction projects bidding risk prediction and } \\
\text { evaluation. } \\
\text { Apply and test NLP system in the industrial settings } \\
\text { of a railway signaling manufacturer. } \\
\text { Support project definition determination automatically } \\
\text { separating requirement statements from non- } \\
\text { requirement statements. }\end{array}$ \\
\hline $\begin{array}{l}\text { Automated } \\
\text { compliance } \\
\text { checking }\end{array}$ & $\begin{array}{l}\text { Semantic machine learning-based text } \\
\text { classification algorithm for classifying clauses } \\
\text { and sub-clauses (Salama and El-Gohary 2016). } \\
\text { NLP and deep learning-based approach, } \\
\text { translating building regulations to computer- } \\
\text { readable format (Song et al. 2018). }\end{array}$ & $\begin{array}{l}\text { Enhance Automated Compliance Checking (ACC) in } \\
\text { AECO industry. } \\
\text { Support Automated Rule Checking activity in AECO } \\
\text { industry. }\end{array}$ \\
\hline $\begin{array}{l}\text { Construction } \\
\text { management }\end{array}$ & $\begin{array}{l}\text { Classification techniques for assigning work } \\
\text { descriptions to task groups based on } \\
\text { construction vocabulary (Martínez-Rojas et al. } \\
\text { 2018). }\end{array}$ & $\begin{array}{l}\text { Automatically classify semantic information about } \\
\text { nature of the work tasks supporting project managers } \\
\text { to manage and achieve project goals. }\end{array}$ \\
\hline $\begin{array}{l}\text { Construction } \\
\text { safety }\end{array}$ & $\begin{array}{l}\text { NLP techniques performed on construction } \\
\text { accident report databases (Zou et al. 2017). } \\
\text { Text mining and NLP to analyze construction } \\
\text { site accident (Zhang et al. 2019). }\end{array}$ & $\begin{array}{l}\text { Improve the efficiency and performance of risk } \\
\text { mitigation Case Base Reasoning (CBR) method. } \\
\text { Prevent reoccurrence of similar accidents enhancing } \\
\text { scientific risk control plans. }\end{array}$ \\
\hline
\end{tabular}

\section{CONCLUSION AND FURTHER DEVELOPMENTS}

The application of NLP and BIM methodology can optimize and automate the numerical definition, validation, and management of requirements in a structured data form. NLP 
supporting information modeling methods allows the application of requirements engineering and management techniques to handle the preliminary phase of the construction processes from a data-driven perspective. As shown above, ontologies are formal and shared entities of a conceptualization. An NLP system could recognize and translate requirement specifications into ontologies. Structured information and knowledge, like ontologies, can be managed in a BIM process from the initial phase of the construction process. With this perspective, NLP and BIM methods can enhance semantic modeling of requirements definition and management of the domain knowledge. Modeling the semantic information contained in text documents through NLP methods during the preliminary phase could avoid or reduce errors during the operation of identifying and translating textual requirements into semi-formal or formal requirements. A decision support system based on ontologies can also be applied to manage the information flow in a data-driven way, overcoming the traditional document-based information flow of the AECO industry, enabling at the same time the application of Requirements Engineering and Management.

\section{References}

Ambriola, V., and Gervasi, V., Processing Natural Language Requirements, Proceedings of the IEEE International Automated Software Engineering Conference, ASE, 36-45, 1997.

Arayici, Y., and Ahmed, V., A Requirements Engineering Framework for Integrated Systems Development for The Construction Industry, Electronic Journal of Information Technology in Construction, 11(May 2014), 35-55, 2006.

Arellano, A., Zontek-Carney, E., and Austin, M. A., Frameworks for Natural Language Processing of Textual Requirements, International Journal on Advances in Systems and Measurements, 2015.

Beetz, J., van Leeuwen, J. P., and de Vries, B., An Ontology Web Language Notation of the Industry Foundation Classes, Proceedings of the 22nd CIB W78 Conference on Information Technology in Construction, 193-198, 2005.

Caldas, C., and Soibelman, L., Automating Hierarchical Document Classification For Construction Management Information Systems, Automation in Construction, 12(4), 395-406, 2003.

Callison-Burch, C., and Osborne, M., A Handbook for Language Engineers, 2004.

Cherpas, C., Natural Language Processing, Pragmatics, and Verbal Behavior, The Analysis of Verbal Behavior, 10, 135-136, 1992.

Espunya i Prat, A., Computational Linguistics: A Brief Introduction, Links and Letters, 1, 9-23, 1994.

Ferrari, A., Gori, G., Rosadini, B., Trotta, I., Bacherini, S., Fantechi, A., and Gnesi, S., Detecting Requirements Defects With NLP Patterns: An Industrial Experience In The Railway Domain, Empirical Software Engineering, 23(6), 3684-3733, 2018.

Gruber, T. R., Toward Principles for The Design of Ontologies Used for Knowledge Sharing, International Journal of Human - Computer Studies, 43(5-6), 907-928, 1995.

Hull, E., Jackson, K., and Dick, J., Requirements Engineering, Second ed., Springer, UK, 2005.

Jain, M., and Pathak, K. K., Applications of Artificial Neural Network in Construction Engineering and Management - A Review, International Journal of Engineering Technology, Management and Applied Sciences, 2(3), 134-142, 2014.

Le, T., Le, C., Jeong, H. D., and Gilbert, S. B., Requirement Text Detection from Contract Packages to Support Project Definition Determination, Advances in Informatics and Computing in Civil and Construction Engineering, Springer International Publishing, 2019.

Lee, J., and Yi, J.-S., Predicting Project's Uncertainty Risk in the Bidding Process by Integrating Unstructured Text Data and Structured Numerical Data Using Text Mining, Applied Sciences, 7(11), $1141,2017$.

Lee, J., Yi, J.-S., and Son, J., Development of Automatic-Extraction Model of Poisonous Clauses in International Construction Contracts Using Rule-Based NLP, Journal of Computing in Civil Engineering, 33(3), 04019003, 2019.

Lenci, A., Montemagni, S., and Pirelli, V., Testo e Computer. Elementi di Linguistica Computazionale, Carocci editore@Aulamagna, Rome, 2005. 
Liu, H., Liu, Y. S., Pauwels, P., Guo, H., and Gu, M., Enhanced Explicit Semantic Analysis for Product Model Retrieval in Construction Industry, IEEE Transactions on Industrial Informatics, 13(6), 33613369, 2017.

Martínez-Rojas, M., Soto-Hidalgo, J. M., Marín, N., and Vila, M. A., Using Classification Techniques for Assigning Work Descriptions to Task Groups on the Basis of Construction Vocabulary, ComputerAided Civil and Infrastructure Engineering, 33(11), 966-981, 2018.

Marzouk, M., and Enaba, M., Text Analytics to Analyze and Monitor Construction Project Contract and Correspondence, Automation in Construction, 98(December 2017), 265-274, 2019.

Mich, L., and Garigliano, R., L'approccio Dell'ingegneria Del Linguaggio Naturale All'analisi Di Domini Aziendali Complessi(January), 2014.

Nedeljkovic, D., and Kovašević, M., Building a Construction Project Key-Phrase Network from Unstructured Text Documents, Journal of Computing in Civil Engineering, 31(6), 1-14, 2017.

Opitz, F., Windisch, R., and Scherer, R. J., Integration of Document- and Model-Based Building Information for Project Management Support, Procedia Engineering, 85, 403-411, 2014.

Pauwels, P., Zhang, S., and Lee, Y. C., Semantic Web Technologies in AEC industry: A Literature Overview, Automation in Construction, 8(5), 55, 2019.

Rumelhart, D. E., Hinton, G. E., and Williams, R. J., Learning Internal Representations by Error Propagation, In Parallel Distributed Processing: Explorations in the Microstructure of Cognition, 567, 1987.

Ryan, K., The Role Of Natural Language In Requirements Engineering, Proceedings of the IEEE International Symposium on Requirements Engineering, 240-242, 1993.

Salama, D. M., and El-Gohary, N. M., Semantic Text Classification for Supporting Automated Compliance Checking in Construction, Journal of Computing in Civil Engineering, 30(1), 2016.

Simeone, D., and Cursi, S., The Role of Semantic Enrichment in Building Information Modelling, TEMA, 2016.

Song, J., Kim, J., and Lee, J.-K., NLP and Deep Learning-based Analysis of Building Regulations to Support Automated Rule Checking System, Proceedings of the 35th International Symposium on Automation and Robotics in Construction (ISARC), 2018.

Waziri, B. S., Bala, K., and Bustani, S. A., Artificial Neural Networks in Construction Engineering and Management, International Journal of Architecture, Engineering and Construction, 6(1), 2017.

Wu, S., Shen, Q., Deng, Y., and Cheng, J., Natural-Language-Based Intelligent Retrieval Engine For BIM Object Database, Computers in Industry, 108, 73-88, 2019.

Young, R. R., The Requirements Engineering Handbook, Artech House, Boston and London, 2004.

Yu, A. T. W., Shen, Q., and Chan, E. H. W., An Analytical Review of the Briefing Practice in Hong Kong's Construction Industry, International Journal of Construction Management, 5(1), 77-89, 2005.

Yu, A. T. W., and Chan, E. H. W., Requirements Management in the Architecture, Engineering and Construction (AEC) Industry: The Way Forward, In CIB Congress 2010, 1-11, 2009.

Yu, A. T. W., Shen, G. Q. P., and Chan, E. H. W., Managing Employers' Requirements in Construction Industry: Experiences and Challenges, Facilities, 28(7), 371-382, 2010.

Zhang, F., Fleyeh, H., Wang, X., and Lu, M., Construction Site Accident Analysis Using Text Mining And Natural Language Processing Techniques, Automation in Construction, 99(January), 238-248, 2019.

Zhang, J., and El-Gohary, N. M., Automated Information Transformation for Automated Regulatory Compliance Checking in Construction, Journal of Computing in Civil Engineering, 29(4), B4015001, 2015.

Zou, Y., Kiviniemi, A., and Jones, S. W., Retrieving Similar Cases for Construction Project Risk Management Using Natural Language Processing Techniques, Automation in Construction, 80(September 2016), 66-76, 2017. 